\title{
PENERAPAN METODE PARAMETRIK PADA PERANCANGAN TAMAN ICHARIBA CHODE UNTUK MENGHADIRKAN DWELLING BAGI LANSIA
}

\author{
Bellinda Juniaty Halomoan ${ }^{1)}$, Suwardana Winata ${ }^{2)}$ \\ 1)Program Studi S1 Arsitektur, Fakultas Teknik, Universitas Tarumanagara, bellindajuniaty@hotmail.com \\ 2) Program Studi S1 Arsitektur, Fakultas Teknik, Universitas Tarumanagara, danarsitek@gmail.com
}

Masuk: 19-01-2021, revisi: 21-02-2021, diterima untuk diterbitkan: 26-03-2021

\begin{abstract}
Abstrak
Aging Population merupakan sebuah fenomena yang akan terjadi pada tahun 20202060 karena penurunan jumlah kelahiran serta peningkatan angka harapan hidup. Jakarta sebagai Ibukota Indonesia diprediksi mengalami peningkatan jumlah Lansia dari $8.47 \%$ (2015) ke $21.79 \%$ (2045). Sehingga akan muncul kompleks-kompleks perumahan ramah lansia dalam kurun waktu 20 sampai 30 tahun ke depan. Proyek Taman Ichariba Chode ini dirancang untuk menjaga lansia tetap aktif, produktif, dan menjalani masa pensiunnya dengan independen. Ini dikarenakan Lansia kerap mengalami penurunan kemampuan fisik, yang kerap menimbulkan rasa terisolasi dan kesepian pada komunitasnya. Metode pengumpulan data secara kualitatif dan kuantitatif terhadap Dokumentasi dan Jurnal Ilmiah tentang Lanjut Usia. Metode Pengolahan Data didasari literatur Problem Seeking: An Architectural Programming Primer dan Perancangan menggunakan Parametrik, yaitu membedah data kepada beberapa parameter desain. Hasil akhir yaitu Leisure Park yang di desain dengan tahapan sebagai berikut: 1 . Perancangan Denah dengan parameter Movement for Elderly, 2. Perancangan zoning dengan parameter Intergeneration, 3. Perancangan solid void potongan dengan parameter Light, Water, and Nature, dan 4. Perancangan fasad dengan parameter color, mass composition, and material. Kesimpulannya, Taman Ichariba chode berfungsi sebagai Leisure Park yang menghadirkan dwelling bagi para lansia. Menggunakan pengolahan data Perancang mendapatkan Fungsi bangunan, Lokasi Tapak, dan Program. Lalu menggunakan Metode Perancangan Parametrik, Kriteria yang mendukung fisiologi lansia diaplikasikan dalam Denah, Tampak, dan Potongan.
\end{abstract}

Kata kunci: Dwelling ; Intergenerasi; Lansia; Leisure Park; Parametrik

\begin{abstract}
The aging population is a phenomenon that will occur in 2020-2060 due to a decrease in the number of births and an increase in life expectancy. Jakarta as the capital city of Indonesia is predicted to have an increase in the elderly population from $8.47 \%$ (2015) to $21.79 \%$ (2045). This leads to speculation that senior-friendly housing complexes will emerge in the next 20-30 years. Ichariba Chode Park is designed to keep Elderly active and productive, so they can enjoy retirement with Independence. Because upon entering senior years, people experience a decrease in physical abilities. It may lead to isolation, even loneliness from the surrounding communities. The data collection method is both Qualitative \& Quantitative Observation of Longevity-related Documentaries and Journal. Data Procession Method based on Problem Seeking: An Architectural Programming Primer then designed into form With Parametric Design Method; As a result, Ichariba Chode Park emerges as a Leisure Park designed with the following stages: 1. Floor plan designed to accommodate Movement for Elderly, 2. Zoning designed to be Intergeneration Friendly, 3. Solid Void of the massing is designed to incorporate Light, Water, and Nature, 4. The facade is designed regarding color, mass composition, and material. In conclusion, within an urban scale Ichariba Chode Park serves as a Leisure Park that promotes dwelling for elderly. Using Data Procession Method, the designer seek Building Function, Site Location, and Program. While using Parametric Design Method helps the designer to apply design parameters into Floor plan, Section Plan, and Facade.
\end{abstract}

Keywords: Dwellingl Elderly; Intergeneration; Leisure Park; Parametrik 


\section{PENDAHULUAN}

\section{Latar Belakang}

Lanjut usia didefinisikan sebagai penurunan, kelemahan, meningkatnya kerentanan terhadap berbagai penyakit dan perubahan lingkungan, hilangnya mobilitas dan ketangkasan, serta perubahan fisiologis yang terkait dengan usia (Aru, 2009) Secara umum seseorang dikatakan lanjut usia (lansia) apabila usianya 65 tahun ke atas. Mobilitas merupakan aspek penting dalam kegiatan sehari-hari yang bisa mendukung otonomi serta partisipasi Lansia. Sayangnya semakin bertambah umur, kebugaran (Fitness ability) berkurang dan meningkatkan resiko jatuh.

Menurut betterhealthwhileaging.net, kondisi jatuh pada lansia dipengaruhi 2 faktor. Faktor pertama adalah Fitness ability: Kemampuan dari tubuh lansia untuk menghindari jatuh. ini termasuk fleksibilitas, keseimbangan, koordinasi dan kekuatan (Flexibility, Balance, Coordination, and Strength). Sedangkan faktor kedua adalah Triggers: Faktor eksternal dari alam atau buatan, maupun kejadian yang bisa mengakibatkan tantangan untuk keseimbangan dan kekuatan lansia. Contohnya permukaan lantai licin, hujan, angin. Selain itu perlu perhatian bahwa isolasi sosial terhadap Lansia dapat mengakibatkan rasa kesepian terutama bila lansia dicabut dari akar budayanya. Berdasarkan dokumentari Loneliness\& Isolation / Aging Matters oleh NPT Reports, beberapa contoh kasus isolasi sosial pada Lansia disebabkan karena penurunan kemampuan fisik, kesulitan menyesuaikan diri terhadap komunitas baru (Perbedaan Budaya), kehilangan pasangan hidup (Janda/ duda), dan kurangnya koneksi dengan Generasi Muda.

\section{Rumusan Permasalahan}

Jurnal ini bermaksud mensimulasikan perancangan bangunan bagi Lansia. Oleh karena itu dipetik dua problem arsitektur yang dianggap relevan dengan penambahan umur. Pertama, seiring bertambah umur kemampuan fisiologi semakin menurun sehingga pergerakan harus difasilitasi. Kedua, lansia tidak dapat dicabut dari akar budayanya karena dapat menyebabkan rasa kesepian.

Maka, rumusan masalah sebagai berikut:

a. Bagaimana Pergerakan dan Akar budaya pada lansia mempengaruhi Proyek secara Fungsi, Tapak, dan Program?

b. Bagaimana Metode Perancangan Parametrik bisa mengkonversikan isu Pergerakan dan Akar budaya lansia menjadi Kriteria Desain?

\section{Tujuan}

Proyek ini dirancang pada tahun 2030- 2050 sebagai antisipasi fenomena Aging Population. Fenomena ini akan meningkatkan jumlah lansia, khususnya di kawasan Perumahan Pluit. Sehingga Ichariba Chode Leisure Park hadir untuk menciptakan dwelling bagi lansia dengan:

a. Proyek hadir sebagai ruang kumpul yang dapat dinikmati seluruh generasi (Lansia, Dewasa, Remaja, maupun Anak-anak), namun memiliki pembagian zonasi yang tegas sehingga lansia juga terjaga privasi dan independence nya. (Intergeneration)

b. Proyek dapat menjaga lansia agar tetap aktif di komunitas dengan program yang disesuaikan konteks masyarakat Chinese di Pluit (Homey)

c. Morfologi Proyek menyesuaikan dengan kemampuan fisik lansia, sehingga mempertimbangkan ketinggian, pencahayaan, pengudaraan, pencapaian ke tapak, (Healing)

\section{KAJIAN LITERATUR}

\section{Dwelling}

Martin Heidegger menggunakan istilah dwelling sebagai konsep menghuni atau cara khas ada (dasein) di dunia. Kunci dari dwelling adalah dalam mengembara (to wander) dan bertahan hidup (to linger). 
Hubungan Man, Space, dan Dwelling

Manusia-ruang-dan dwelling/bangunan memiliki hubungan layaknya segitiga yang menggambarkan lingkup arsitektur.

a. Hubungan manusia (man) dan dwelling (building) termanifestasi dalam bentuk level fisik dan praktis, terlihat dalam struktur fisik dan aksi dalam bangunan.

b. Hubungan manusia (man) dan ruang (space) termanifestasi dalam level memori, interaksi antara manusia dengan lingkungannya.

c. Hubungan ruang (space) dan dwelling (building) mengandung level abstrak dari ruang: level konsep dan struktur dari arsitektur.

d.

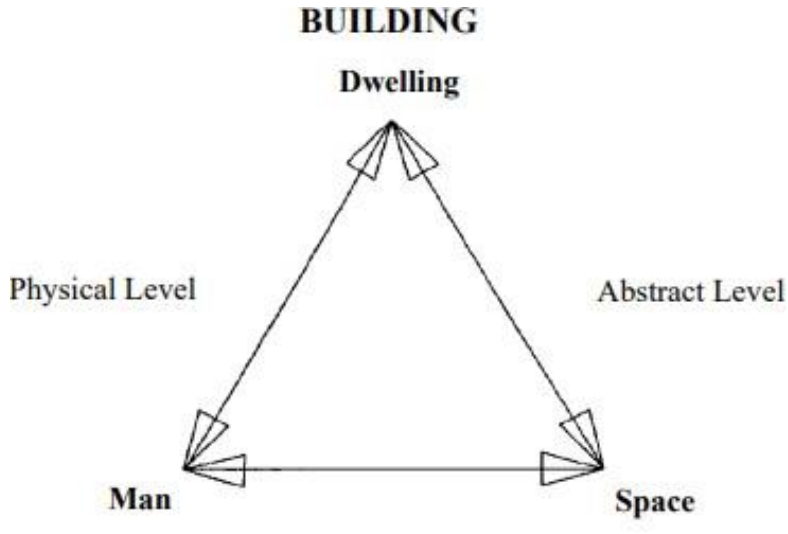

Memory Level

Gambar 1. Hubungan antara manusia (man), ruang (space), dan dwelling (building) Sumber: Orientation, Identification, Representation: Space and Perception in Architecture, 2015

Pada Kasus Lansia, didasari 5P Ecological Model of Active Aging (Lak A, R. P. (2020): Person, Process, Place, Policymaking, dan Prime. Dapat Disimpulkan bahwa faktor Person bicara pada aspek Memori, Process pada aspek Abstrak, dan Place pada aspek Fisik. Ketiga faktor ini akan diterjemahkan pada Bab 3 (Metode Desain) sebagai data-data yang perlu dikumpulkan dalam proses perancangan.

\section{Literatur Problem Seeking: An Architectural Programming Primer}

Pada Proyek ini, Metode Pengolahan Data didasarkan oleh buku Problem Seeking: An Architectural Programming Primer oleh William M. Peña Steven A. Parshall. Ini dilakukan dengan pengertian dasar bahwa bangunan yang baik tidak terjadi begitu saja, namun dirancang untuk terlihat bagus dan memiliki performa tinggi. Terdapat 4 faktor yang ditinjau: Function, Form, Economy, Time dengan 5 Prioritas : 1. Establish Goals, 2. Collect and Analyze Facts, 3. Uncover and Test Concepts, 4. Determine Needs, 5. State Problems.

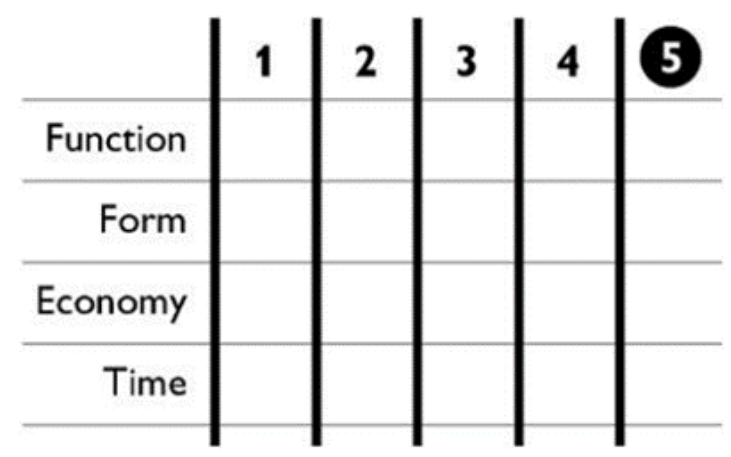

Gambar 2. Tabel Pemetaan Data untuk menemukan Problem Arsitektur Sumber: Problem Seeking: An Architectural Programming Primer, 1977 


\section{Environment for better Elderly Physiological Health}

Berdasarkan teori kebutuhan manusia oleh Abraham Maslow, disebutkan bahwa seorang lansia memiliki prioritas sebagai berikut: 1. Physiological Needs, 2. Safety Needs, 3. Belonging and love Needs, 4. Esteem Needs, 5. Self-Actualization Needs. (Zulke K. Maslow Project).

Mendukung fisiologi lansia menjadi prioritas rancangan ini karena penurunan massa otot akibat pembelahan sel menjadi akar dari proses penuaan.

Berikut adalah beberapa contoh implementasi desain yang dapat mempengaruhi Physiological Needs pada lansia.

Tabel 1. Aging Needs, Design Variable, dan Design Implementation terhadap kebutuhan fisiologi lansia

\begin{tabular}{|c|c|c|}
\hline Aging Needs & Design Variable & Implementation \\
\hline \multirow[t]{8}{*}{$\begin{array}{l}\text { Physical activity, } \\
\text { obesity, mobility } \\
\text { impairment }\end{array}$} & Site Accesibility & $\begin{array}{l}\text { (+)Continuous, barrier-free sidewalks, four-way stop signals, and } \\
\text { pedestrian amenities, access to recreational facilities } \\
\text { (-) Poor Transportation, Discontinuous/ Uneven Sidewalk, Curbs, } \\
\text { Noise, Inadequate Lighting, Temperature Extremes } \\
\text { (-) Poor street conditions, heavy traffic, and excessive noise. Car } \\
\text { dependent neighborhoods }\end{array}$ \\
\hline & $\begin{array}{l}\text { Basic } \\
\text { Physiological } \\
\text { Requirements }\end{array}$ & $\begin{array}{l}\text { (-)Windows that are impossible for the arthritic hand to manipulate; } \\
\text { kitchen storage that requires back-breaking bending or a reaching } \\
\text { device to access; doorknobs that are difficult to turn; controls that are } \\
\text { impossible to read; and furniture that is difficult to enter or exit }\end{array}$ \\
\hline & $\begin{array}{l}\text { Sensory Aspect: } \\
\text { Visual }\end{array}$ & $\begin{array}{l}\text { Problems of visual loss: Create a high level of diffused light } \\
\text { on critical surfaces where light is needed (Hiatt, 1980). }\end{array}$ \\
\hline & & $\begin{array}{l}\text { To discern certain color intensities (color differences between green } \\
\text { and blue are often confused), and to judge distances. }\end{array}$ \\
\hline & $\begin{array}{l}\text { Sensory Aspect: } \\
\text { Hearing }\end{array}$ & $\begin{array}{l}\text { Increasing the absorption of unwanted sound in spaces in which } \\
\text { conversations take place and minimizing reverberation and } \\
\text { background noise }\end{array}$ \\
\hline & & $\begin{array}{l}\text { Signs-The strategic use of information } \\
\text { Perceptual access - a view to a familiar exterior landmark or a view } \\
\text { through the building to an important unifying element }\end{array}$ \\
\hline & Way Finding & $\begin{array}{l}\text { Architectural differentiation - Treating each section or region within a } \\
\text { building with different wall coverings or floor materials }\end{array}$ \\
\hline & & $\begin{array}{l}\text { Planned configuration-The layout or shape of the floor plan can } \\
\text { influence the ease with which one can build a mental map }\end{array}$ \\
\hline
\end{tabular}

Sumber: https://www.maturitas.org/article/S0378-5122(09)00257-6/fulltext, 2020

\section{METODE}

Metode Pengumpulan Data dilaksanakan secara Observasi data Kualitatif dan Kuantitatif. Terdapat tiga Data utama yaitu Dwelling untuk Lansia, Konteks Tapak Pluit, serta informasi Fisiologi Lansia. Metode Analisis Sintesis/ Pengolahan data diacukan terhadap literatur Problem Seeking oleh William Pena sehingga menghasilkan hasil akhir Fungsi, Tapak, dan Program.

Metode Perancangan menggunakan Parametric Design Method, dimana Fungsi, Tapak, dan Program diolah menjadi beberapa kriteria desain untuk perancangan zonasi, denah, tampak, dan potongan. 


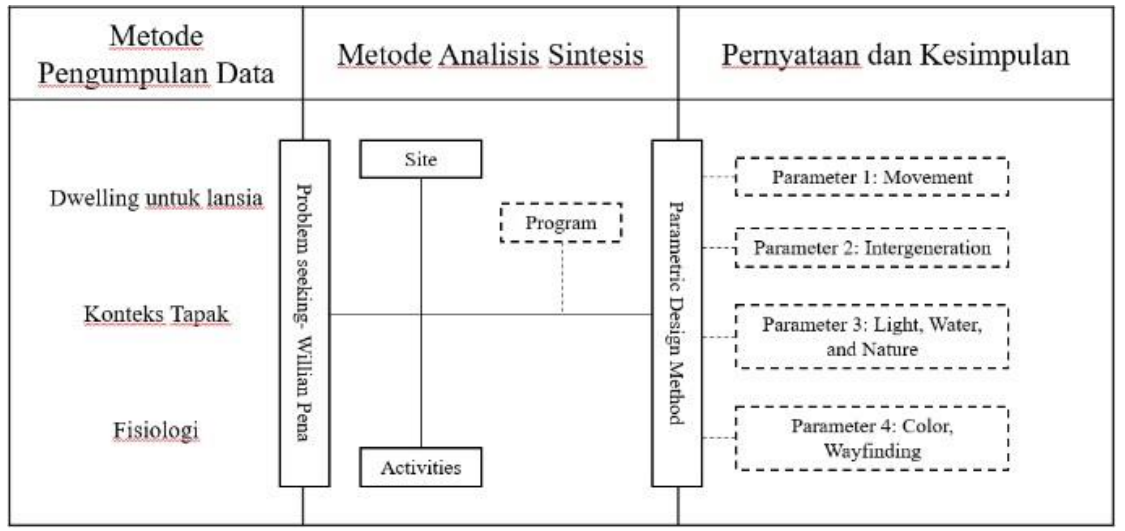

Gambar 3. Kerangka Metode Penelitian

Sumber: Penulis, 2021

\section{DISKUSI DAN HASIL}

\section{Pemilihan Tapak: Pluit, Jakarta Utara}

Berdasarkan perumusan masalah yang diprediksi muncul akibat Aging Population, maka ditentukan kriteria tapak yang dianggap ramah lansia sebagai berikut.

a. Lokasi dengan kepadatan/ prediksi kepadatan lansia tinggi

b. Area perumahan elit karena infrastruktur kesehatan, jaringan jalan, urban fabric yang lebih tertata sehingga menunjang wellbeing lansia.

c. Dapat dianalisa akar budayanya sehingga bisa diaplikasikan ke tahun pembangunan (2030-2050) dengan user Generasi X.

Pada skala kawasan, area Jakarta Barat-Utara menjadi terpilih karena memiliki jumlah lansia tertinggi di Jakarta. (2015, BPS DKI Jakarta). Penulis juga melakukan pemetaan Perumah Elit dan Perumahan Tua di Jakarta, ini untuk memastikan kawasan yang dipilih memiliki fasilitas serta urban fabric yang tertata untuk mempermuda aksesibilitas lansia. Namun kawasan juga harus mempunyai akar budaya yang sesuai dengan Generasi X. Untuk itu dipilih Kelurahan Pluit, Kecamatan Penjaringan, Jakarta Utara. Kelurahan Pluit memiliki jumlah penduduk sebanyak 44.210 jiwa terdiri dari 23.000 jiwa lakilaki dan 21.210 jiwa perempuan. Kawasan ini terhitung elit dengan Fasilitas yang cukup komplit. Dari sarana perekonomian (Pasar Muara Karang, Pasar Muara Angke, Pasar Pluit) lalu rekreasi juga terdapat di Pluit Village, Baywalk Mall, Emporium Mall dan Pluit Junction. Area ini juga difasilitasi sarana pendidikan maupun sarana kesehatan.

Pada skala distrik, dilakukan Analisa berdasarkan Problem Seeking: An Architectural Programming Primer oleh William M. Pena terhadap Function Concepts serta Form Concepts yang membantu penentuan RW serta pemilihan tapak.

Function Concepts:

- Intergeneration Living yaitu melibatkan Lansia agar bisa berkontribusi ke masyarakat generasi lain.

Form Concepts antara lain:

- Design for Social Encounter (mempertimbangkan tipologi the Branch, Street, atau Cul de sac)

- Desain untuk akomodasi penurunan indra

- Green \&Nature Oriented Design

Sehingga RW 6-10 dipilih karena

a. Zonasi kawasan lebih ke arah perumahan dibanding komersial, jika dibandingkan dengan Muara Karang serta Pantai Indah Kapuk

b. Area lebih sepi, lebih ramah pejalan kaki karena tidak ramai mobilitas mobil

c. Memiliki banyak potensi Intergenerasi 


\section{Problem Seeking}

Proses programming pada proyek ini mengacu literatur Problem Seeking: An Architectural Programming Primer oleh William M. Pena. Dimana terdapat empat jenis problem arsitektural yaitu Function, Form, Economy, dan Time.

Empat problem arsitektur ini di urutkan dengan 5 prioritas: (1) Goals, (2) Facts, (3) Concepts, (4) Needs, (5) Problem.

Tabel 2. Function (People, Activities, Relationships)

\begin{tabular}{ll}
\hline \multirow{2}{*}{ Goals } & $\begin{array}{l}\text { Menyediakan wadah berkumpul bagi Lansia dengan aksesibilitas ke perumahan } \\
\text { yang nyaman, sehingga menjaga Lansia tetap aktif (mencegah Demensia, } \\
\text { Disabilitas, dan Kesepian) }\end{array}$ \\
\hline \multirow{3}{*}{ Facts } & $\begin{array}{l}\text { Aktifitas berkumpul lansia } \\
\text { 1. Fisik } \\
\text {-Berenang, Jalan Pagi, Bulutangkis, Yoga, Taichi } \\
\text { 2. Kognitif } \\
\text { 3. Sosial (Mayoritas Tiongkok Medan) } \\
\text {-Belanja di Pasar, Makan, Belanja di Shopping Centre, Karaoke, Arisan }\end{array}$ \\
\hline \multirow{2}{*}{ Noncepts } & $\begin{array}{l}\text { Intergeneration Living: Melibatkan Lansia agar bisa berkontribusi ke masyarakat } \\
\text { muda. }\end{array}$ \\
\hline \multirow{2}{*}{ Problems } & $\begin{array}{l}\text { Program yang meningkatkan aspek fisik, kognitif, dan sosial lansia. Tidak Lupa harus } \\
\text { sesuai dengan akar budaya. }\end{array}$ \\
\hline
\end{tabular}

Tabel 3. Form (Site, Environment, Quality)

\begin{tabular}{ll}
\hline Goals & $\begin{array}{l}\text { Menghimpun area perumahan rawan bencana akibat penurunan indra (visual, } \\
\text { pendengaran, dan mobilitas), rawan polusi dan memiliki keindahan alam }\end{array}$ \\
& 1. Jalan di Kelurahan Pluit umumnya tidak memiliki jalur pedestrian. \\
2. Fasilitas Kesehatan berada dalam radius $1 \mathrm{~km}$ dari tapak. \\
3. Jalan sekunder di pluit tetap mengutamakan kendaraan bermotor (polusi dan \\
bising) \\
4. Tidak ada lampu jalan untuk malam hari \\
5. Jl. Pluit sakti menghubungkan Kali Pluit dan Waduk Pluit
\end{tabular}

Tabel 4. Economy (Initial Budget, Operating Cost, Life Cycle Cost)

\begin{tabular}{ll}
\hline Goals & Menfasilitasi Lansia mencari nafkah kedepannya \\
\hline \multirow{2}{*}{ Facts } & $\begin{array}{l}\text { Pemerintah telah meningkatkan batas umur produktif dari } 60 \text { menjadi } 65 \text { tahun } \\
\text { karena Aging Population. }\end{array}$ \\
\hline Concepts & - \\
\hline Needs & - \\
\hline Problems & - \\
\hline
\end{tabular}


Tabel 5. Time (Past, Present, Future)

\begin{tabular}{ll}
\hline Goals & Antisipasi fenomena Aging population \\
\hline Facts & $\begin{array}{l}\text { Pada tahun } 2050 \text { Lansia akan meningkat dari } 8.47 \% \text { ke } 21.79 \% \\
\text { Kemampuan ekonomi rata-rata menurun sehingga lansia disarankan untuk tetap Produktif }\end{array}$ \\
\hline Concepts & $\begin{array}{l}\text { Mengkonversikan lantai dasar sebagai ruang public komersial sehingga lansia dan keluarga } \\
\text { pemilik rumah bisa kerja dari rumah. }\end{array}$ \\
\hline Needs & Peluang kerja untuk lansia ketika proyek berdiri 2030 - 2055 \\
\hline Problems & $\begin{array}{l}\text { Bagaimana antisipasi terhadap fenomena Aging Population bisa mempengaruhi jenis aktivitas } \\
\text { lansia yang terjadi dalam bangunan? }\end{array}$ \\
\hline
\end{tabular}

Sumber: Penulis, 2021

Proses Programming di atas dilaksanakan sejalan dengan penentuan lokasi tapak yang sebagian besar ditentukan lewat pembedahan Form Needs dan Form Problems. Sedangkan aktivitas serta program bangunan akan berpacu pada Function dan Time.

\section{Problem Solving using Parametric Design Methods}

Parametric design adalah cara menemukan bentuk berbasis beberapa parameter terpisah (independent parameters) yang disesuaikan dengan design criteria. Parameter ini kemudian dikonversi kepada implementasi geometris (Design Methods/ Kari Jormakka, 2008, p.75). Namun karena keterbatasan perancang dalam menggunakan aplikasi serta pengolahan data numerikal, maka parameter akan diimplementasikan ke rancangan menurut skala prioritas.

Terdapat empat tahapan dalam pembentukan gubahan massa bangunan ini. Setiap tahapan dilandasi dengan parameter seperti berikut

a. Floor Plan: Parameter: Movement for elderly

b. Zoning and circulation: Parameter: Intergeneration Living (Public and Private spaces)

c. Section cuts: Parameter: Light, water, and nature for elderly

d. Façade: Parameter: Wayfinding (Color, mass composition, material)

Penggubahan massa tahap pertama dilaksanakan dengan pertimbangan site context, Tapak membelah dua area dengan level privasi berbeda: Jl. Pluit Sakti (Komersial) dan Kompleks perumahan Pluit Sakti. Sehingga pada (Gambar 6) dilakukan berbagai eksperimen radius lingkaran, ini terinspirasi proyek Copenhagen Zoo oleh Bjarke Ingels Group.

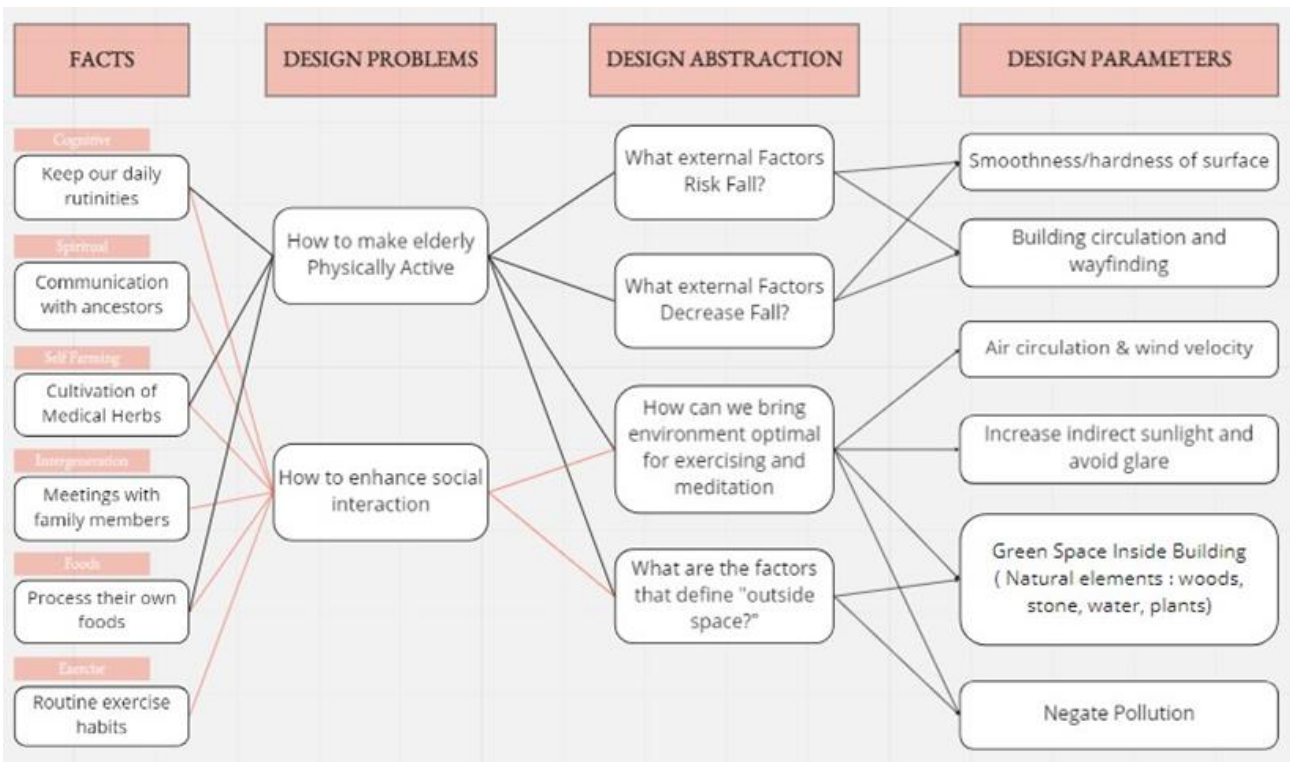

Gambar 4. Penjabaran Parameter Desain

Sumber: Penulis, 2021 
Pada tabel di atas, dilakukan pembedahan fakta berupa enam prinsip gaya hidup sehat Lansia berdasarkan Dokumentari Longetivity Okinawa. Enam prinsip ini dihubungkan dengan Rumusan Masalah (1.4) sehingga menghasilkan parameter desain sebagai berikut:

1. Kelicinan (Smoothness) dan Kekerasan (Hardness) dari permukaan

2. Sirkulasi bangunan dan pencarian jalan (Wayfinding)

3. Sirkulasi udara dan kecepatan angin (Air Circulation)

4. Menghindari cahaya matahari silau U.V. (Glare)

5. Green space inside building

6. Mengurangi polusi (Negate pollution)

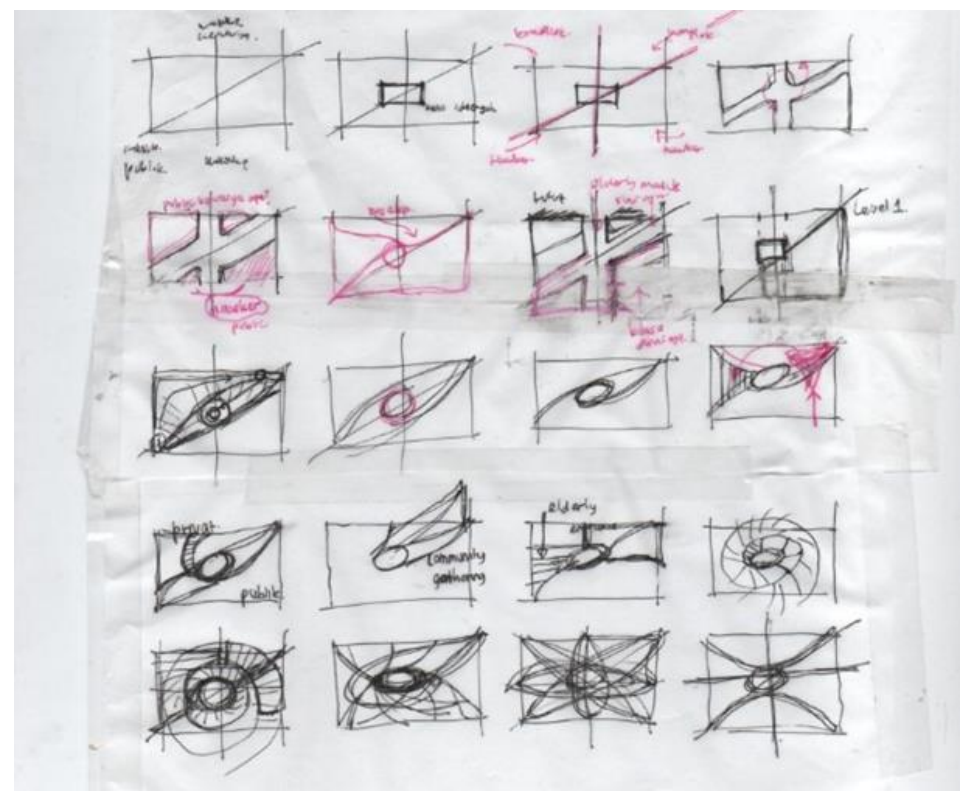

Gambar 5. Eksperimen bentuk Loop pada Floor Plan Sumber: Penulis, 2021

Tahap kedua, setelah eksperimen pada bentuk dasar, penulis mulai mempraktikan program bangunan ke zoning dan sirkulasi. Ramp dirancang untuk naik perlahan-lahan setinggi $90 \mathrm{~cm}$. Kemiringan ramp disesuaikan dengan ergonomi lansia. Pada Gambar 7, zonasi kegiatan dibagi menjadi 3:

1. Intergeneration (Public): untuk semua generasi dengan jenis kegiatan publik, ruangan yang dihasilkan antara lain Hawker, Taichi Field, Gardening Area.

2. Intergeneration (Community): untuk semua generasi namun fokus ke komunitas, ruangan untuk Komunitas Masak, Komunitas Seni, dan Komunitas Bisnis.

3. Elderly Only: dikhususkan untuk lansia, terdapat Dapur, Ruang Karaoke, Ruang Medical Checkup, Komunitas Mahyong, Area Karaoke dan Nonton Bareng, serta Bar.

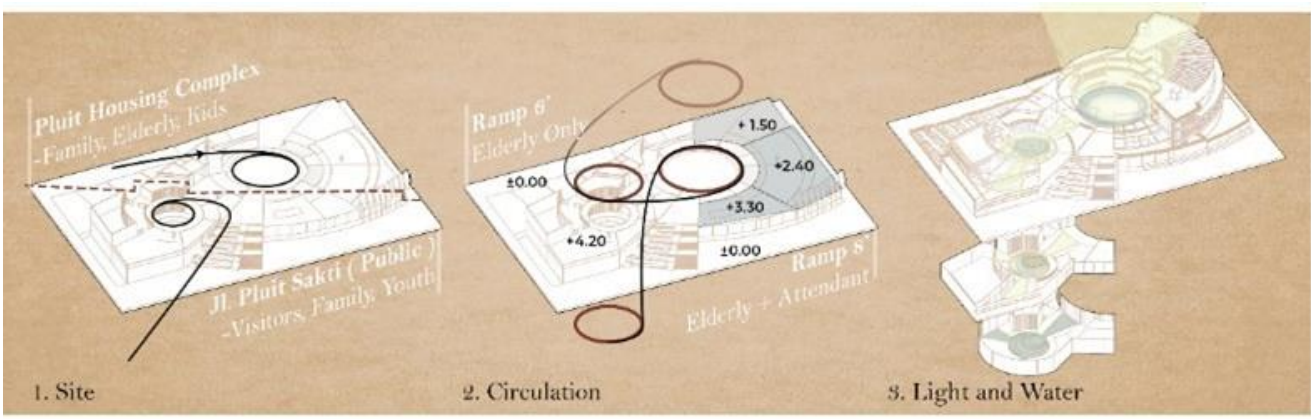

Gambar 6. Proses gubahan massa secara bertahap

Sumber: Penulis, 2021 

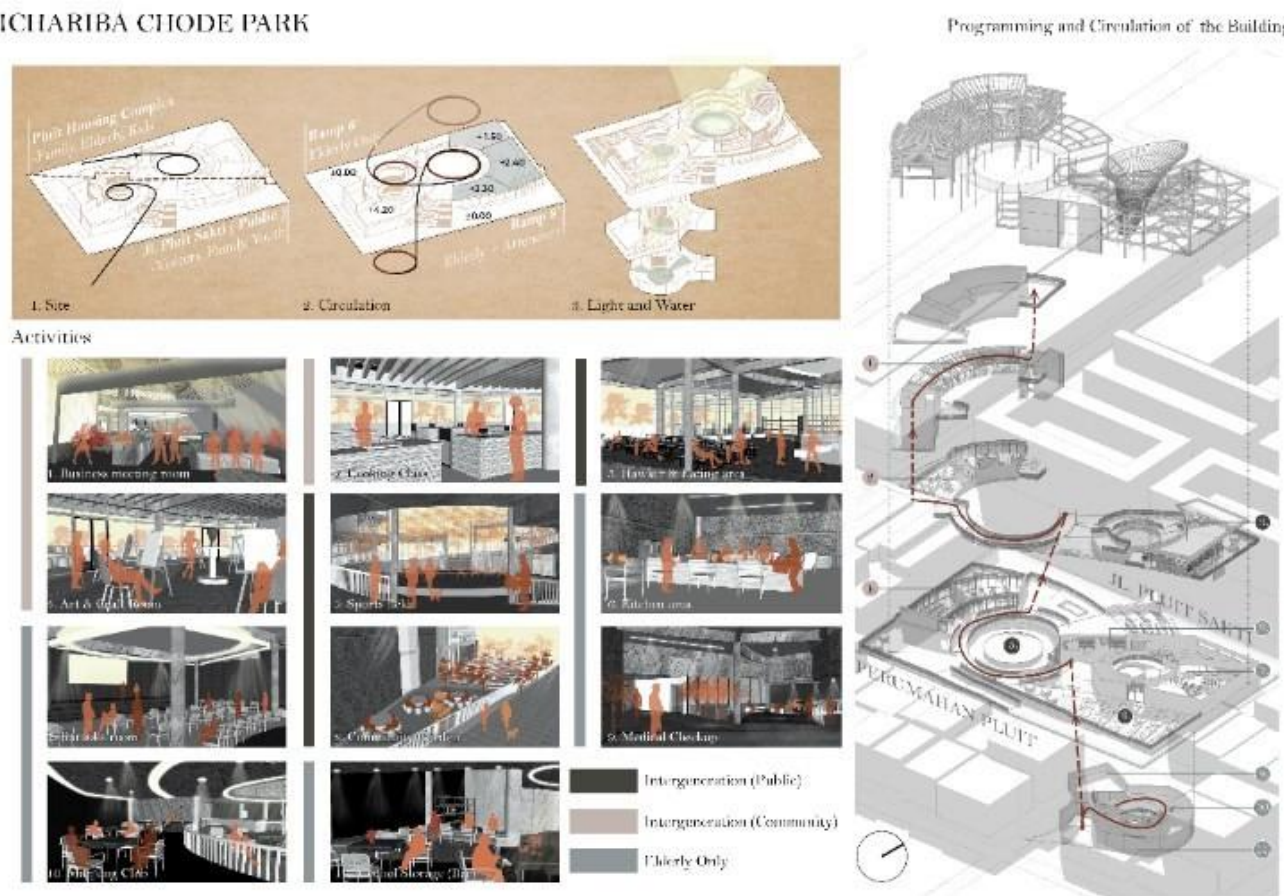

Gambar 7. Program dan sirkulasi diimbangi pencahayaan Sumber: Penulis, 2021

Implementasi Cahaya, Air, dan Vegetasi pada tahap ketiga dilaksanakan bersamaan dengan tahap dua, pada Gambar 8, bisa dilihat bahwa semakin privat zonasinya maka perancang lebih memilih pencahayaan buatan dibanding pencahayaan alami. Ini untuk menghindari Glare/Cahaya matahari jam 12 siang. Beberapa area seperti Hawker dan Taichi Field juga diberi tumbuhan dan aliran air untuk meredakan terik.

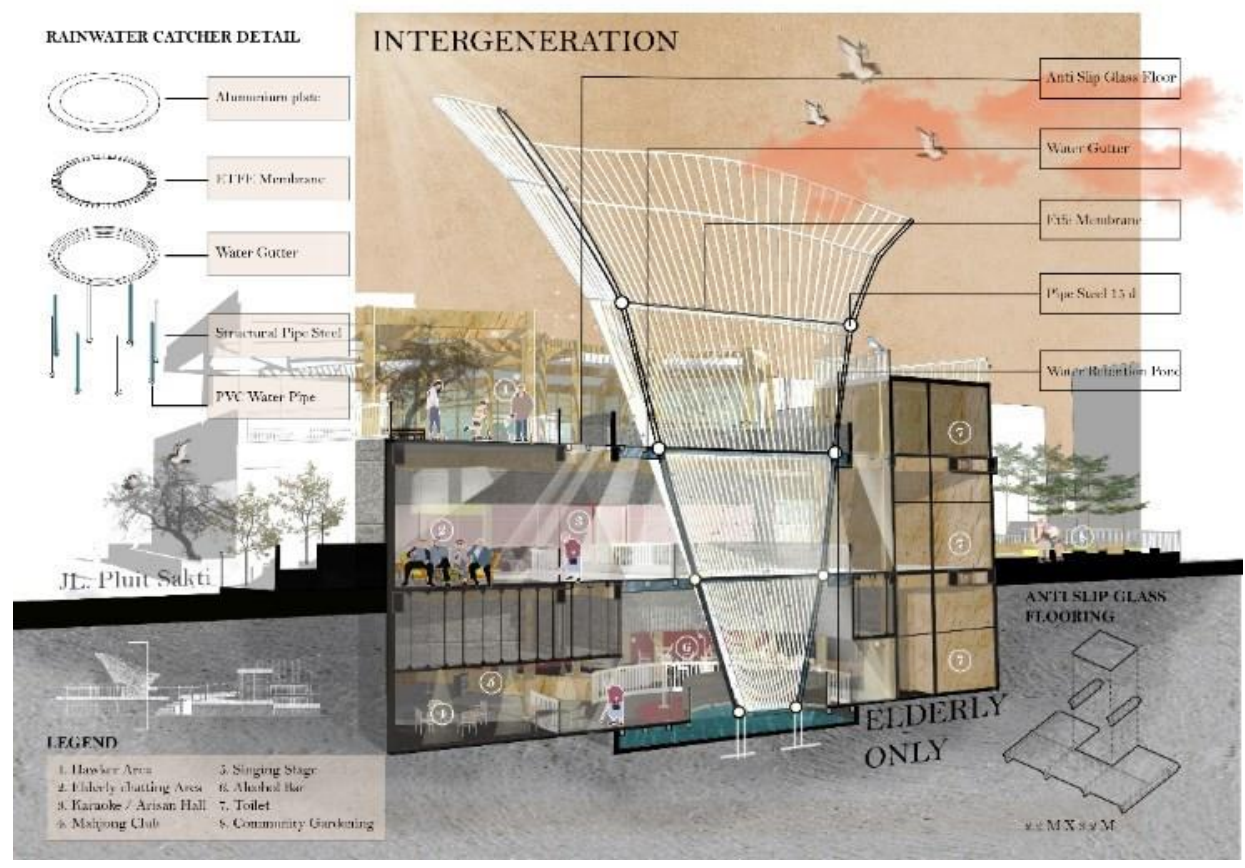

Gambar 8. Potongan Perspektif menunjukan perbedaan cahaya tiap zonasi Sumber: Penulis, 2021

Pada tahapan terakhir, perancang menentukan material pada setiap area bangunan. Dibawah merupakan tiga konsep suasana yang menggambarkan tiga zonasi berbeda Taman Ichariba Chode. 


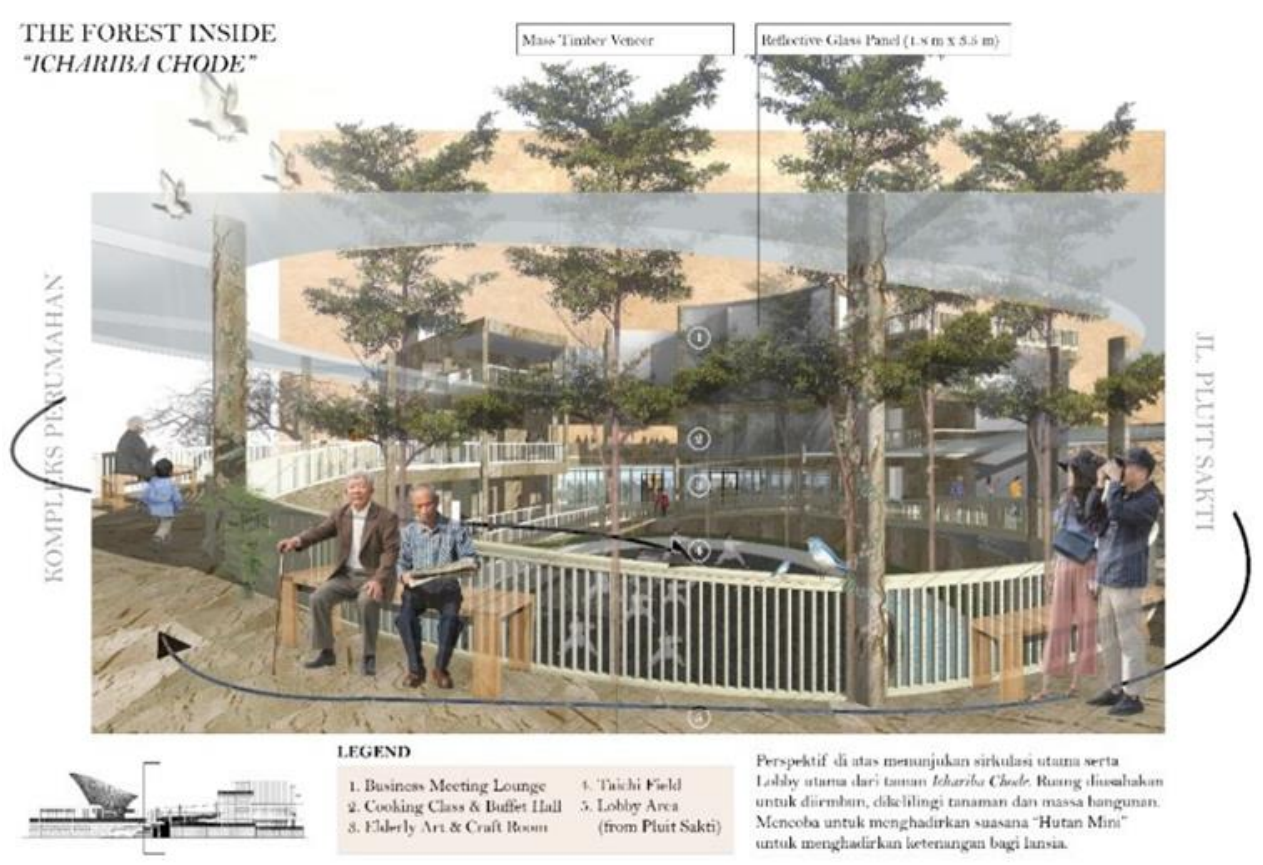

Gambar 8. Konsep suasana Zona Intergeneration (Community) Sumber: Penulis, 2021

Zona Intergenerasi khusus Komunitas merupakan focal point dari rancangan ini. Material Mass Timber Veneer merupakan Kayu sintetis yang diharapkan dapat memberi kesan seperti didalam hutan. Selain itu Komposisi pohon pinus juga disusun sehingga menutupi Jalan Pluit Sakti yang ramai, Material Kaca pada bangunan komunitas juga diletakkan untuk refleksi pohon sehingga orang di Lapangan Taichi merasa seperti di dalam hutan.

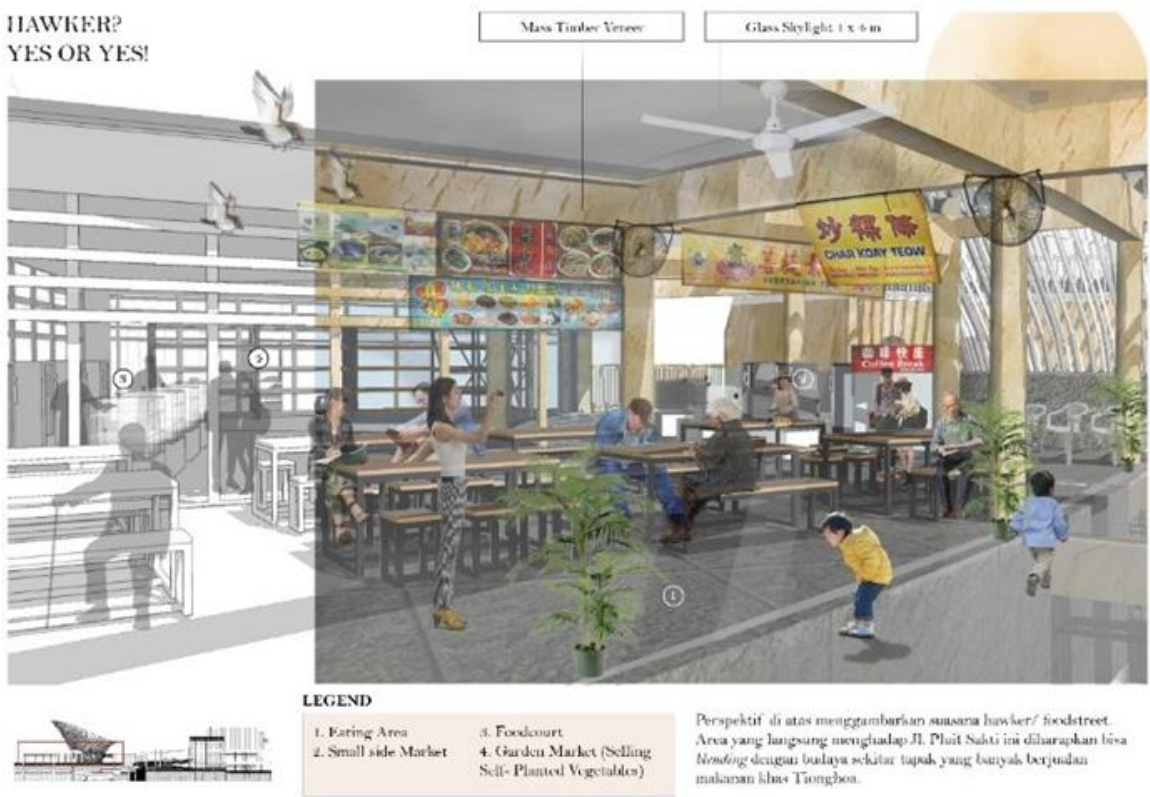

Gambar 8. Konsep suasana Zona Intergeneration (Community) Sumber: Penulis, 2021

Zona Intergenerasi Publik meliputi area makan (Hawker) dan toilet umum. Area ini menghadap Jl. Pluit Sakti yang dipenuhi ruko makanan. Konsep suasana dari area ini mengikuti Pasar Muara Karang dimana banyak warga lokal keturunan Chinese berkumpul di Hawker untuk makan pagi maupun malam bersama kerabat. 


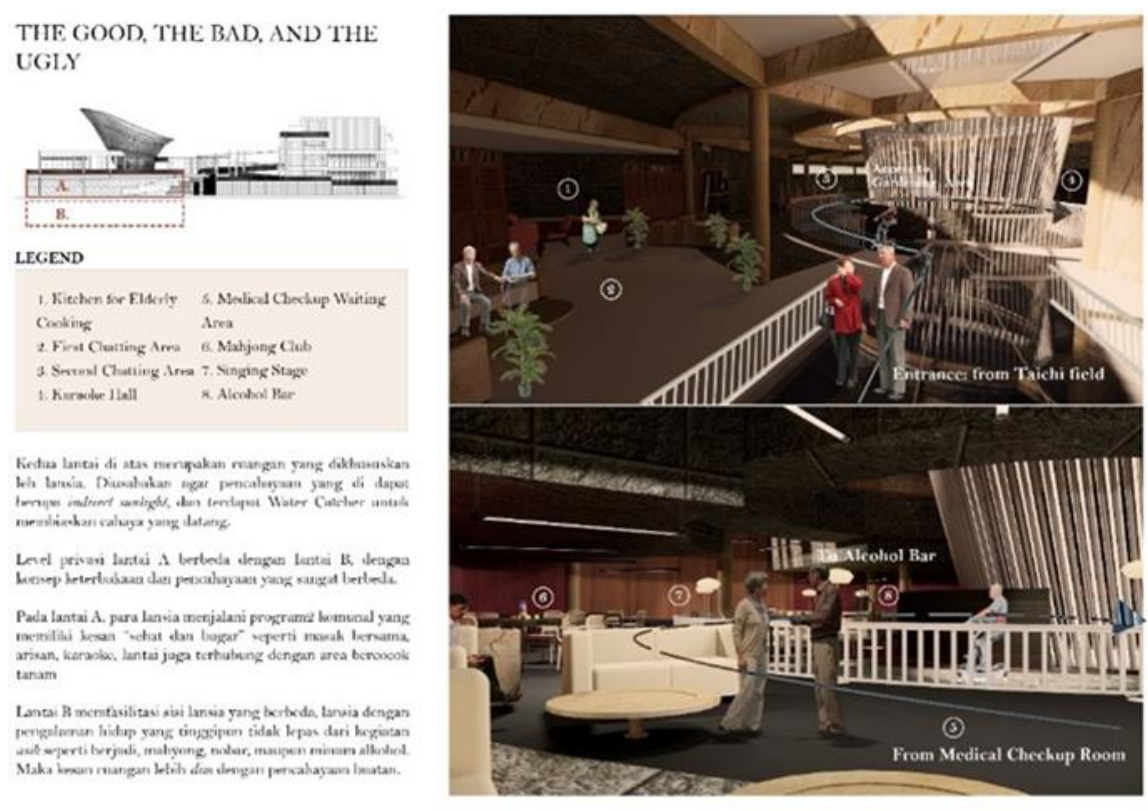

Gambar 8. Konsep suasana Zona Intergeneration (Community)

Sumber: Penulis, 2021

Pada area khusus lansia, Level privasi lantai A berbeda dengan lantai B. Pada lantai A, para lansia menjalani program2 komunal yang memiliki kesan "sehat dan bugar" seperti masak bersama, arisan, karaoke, lantai juga terhubung dengan area bercocok tanam Lantai B memfasilitasi sisi lansia yang berbeda, lansia dengan pengalaman hidup yang tinggipun tidak lepas dari kegiatan asik seperti berjudi, mahyong, nobar, maupun minum alkohol. Maka kesan ruangan lebih dim dengan pencahayaan buatan.

\section{KESIMPULAN DAN SARAN}

\section{Kesimpulan}

Lanjut Usia adalah sebuah kondisi penurunan, kelemahan, dan peningkatan kerentanan secara fisiologis, sosial, terkadang mental. Untuk merancang proyek arsitektur yang sesuai dengan dwelling bagi lansia, penulis menggunakan 2 macam metode: Metode Analisis Sintesis dan Metode Perancangan Bangunan.

Menggunakan Metode Analisis Sintesis berdasarkan Problem Seeking: An Architectural Programming Primer, Penulis merancang Taman Ichariba Chode dengan peranan sebagai berikut:

a. Secara perancangan kota, berfungsi sebagai Leisure Park yang menaungi Lansia agar memiliki aktivitas diluar rumah.

b. Secara perancangan wilayah, kondisi tapak berada di antara area komersial dan area perumahan. Lokasi juga murah dicapai pedestrian sehingga nyaman untuk Lansia yang tinggal di kompleks perumahan sekitar.

c. Secara perancangan Bangunan, pembagian program pada Taman Ichariba Chode meliputi area khusus Lansia (Area kebun, karaoke dan arisan, area judi dan nonton bersama, area Intergenerasi Privat (Ruang komunitas memasak, gambar, bisnis), dan area Intergenerasi Publik (Hawker, pasar).

Perancangan Bentuk menggunakan Metode Perancangan Parametrik, dimana faktor-faktor Environment for Better Physiological Health diaplikasikan ke bentuk perancangan. Hasil perancangan diaplikasikan pada Denah, Zonasi \& Sirkulasi, Potongan, dan Fasad.

a. Floor Plan: Parameter: Movement for elderly

b. Zoning and circulation: Parameter: Intergeneration Living (Public and Private spaces)

c. Section cuts: Parameter: Light, water, and nature for elderly

d. Façade: Parameter: Wayfinding (Color, mass composition, material) 
Pada aplikasi bentuknya, Taman Ichariba Chode memiliki kemiringan ramp, sirkulasi, serta ketinggian bangunan yang disesuaikan ergonomi orangtua. Selain itu pencahayaan, air, dan tanaman juga disesuaikan dengan aktivitas sesuai konteks tapak.

\section{Saran}

Studi tentang pengaruh peningkatan usia (Aging) terhadap perancangan ruang masih sangat minim, sehingga belum banyak literatur buku yang mengulas topik ini. Berbagai macam riset mengenai topik lanjut usia/ Aging umumnya dilaksanakan dalam sektor kesehatan, maupun sosial namun diskursus perancangan ruang masih sangat terbatas. Penambahan umur bukanlah sesuatu yang patut diterima begitu saja adanya. Penambahan umur harus dianggap sebagai sebuah penyakit yang mampu disembuhkan atau dicegah gejalanya. Menggunakan Metode Desain Parametrik, jurnal ini masih memiliki potensi perkembangan yang tidak terhingga, sehingga para pembaca sangat disarankan untuk menyesuaikan penggunaan metode berdasarkan informasi terbaru.

\section{REFERENSI}

BPS DKI Jakarta. (2017, Januari 30). Jumlah Penduduk dan Rasio Jenis Kelamin Menurut Kabupaten.

Heidegger. (1971). Dwelling Thinking Building, from Poetry, Language, Thought, translated by Albert Hofstadter. New York: Harper Colophon Books.

Irawati, M. (2020, April 11). Riset spasial ungkap risiko penyebaran coronavirus level kelurahan dan pasar tradisional di Jakarta.

Jones, K. (2020, January 15). The Problem of an Aging Global Population, Shown by Country. Retrieved from VisualCapitalist.com: https://www.visualcapitalist.com/aging-global- populationproblem/

Jormakka, K. (2008). Basic Design Method. Basel: Birkhäuser

Kim, D. (2016). Correlation between physical function, cognitive function, and health-related quality of life in elderly persons. Journal of Physical Theraphy Science. Retrieved from https://www.ncbi.nlm.nih.gov/pmc/articles/PMC4932071/

Norberg-Schulz, C. (1985). The Concept of Dwelling: on the way to figurative architecture. New York : Rizzoli

PENA, WILLIAM M., PARSHALL, STEVEN A.. (2001). Problem seeking (4). New York: John Wiley.

Rahardjo, T. B., Maliki, Mulan, E., Suratmi, T., Nugraha, S., \& Agustin, D. (2019). Healthy Ageing Policy and Program in Indonesia. Japan Center for International Exchange, (pp. 1-35). https://ahwin.jcie.org/wp-content/uploads/2020/06/8.Session1_TribudiWahyuniRahardjo.pdf

Rotenberg, J. F. (2011). Integrated ageing: an architectural strategy for the ageing baby boomers. Digital Commons @ Ryerson, 117.

Santoso, J. (2011). The Fifth Layer of Jakarta. Jakarta: Centropolis Universitas Tarumanagara.

UNDP, Economic Research Institute for ASEAN and East Asia. (2018, December 18). Project 2045 Executive Summary Indonesia - Japan 2045: A Joint Project of Two Maritime Democracies. 